\title{
ОСОБЕННОСТИ НАСЛЕДОВАНИЯ ОБЯЗАННОСТЕЙ ПО КРЕДИТНОМУ ДОГОВОРУ
}

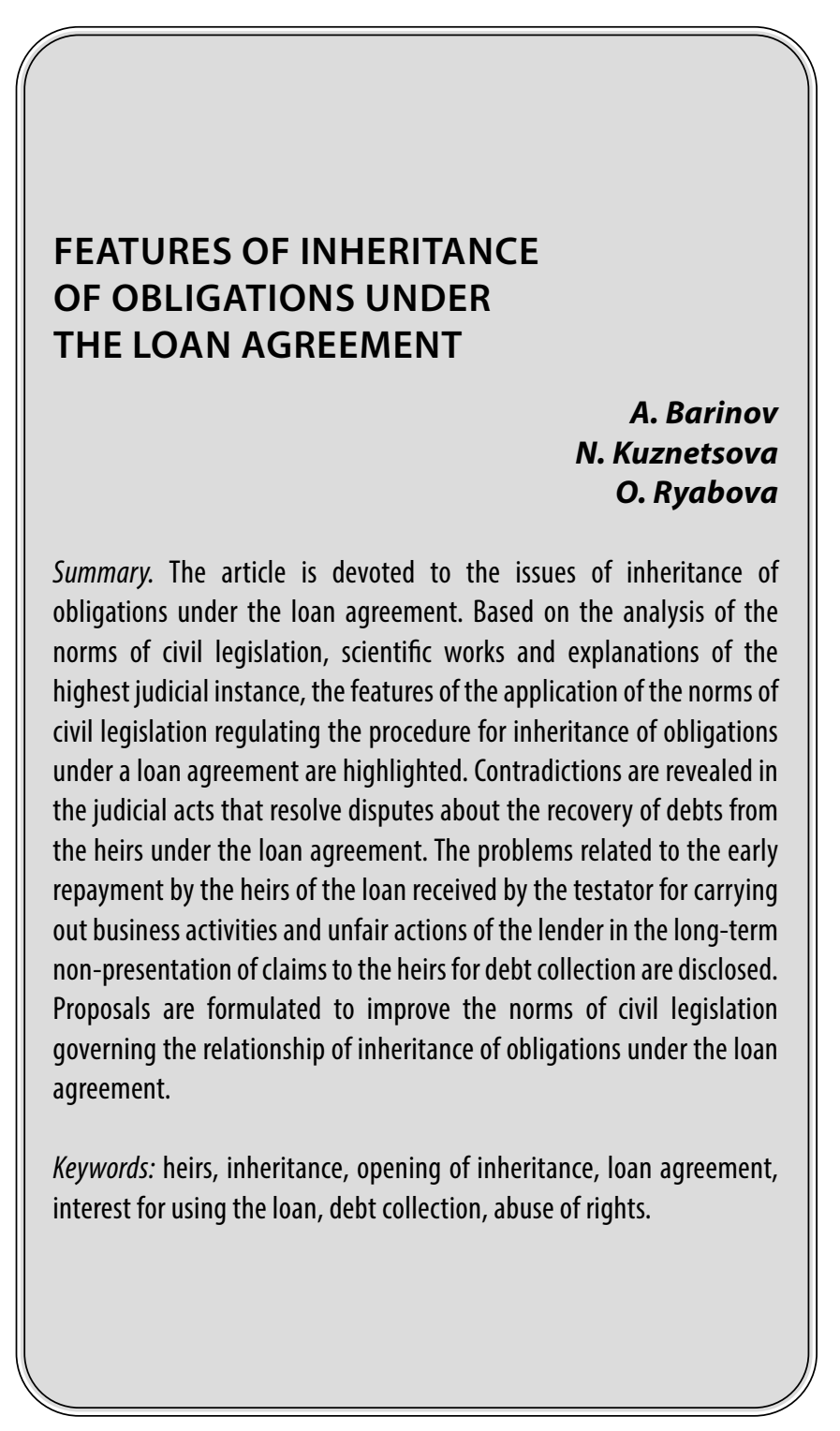

$\mathbf{P}$ азвитие финансового рынка в России привело к тому, что у граждан кроме различного вида имущества появились и долговые обязательства, связанные, как правило с получение кредитов у банков, в том числе и под залог недвижимости (ипотека), микрозаймы взятые у микрофинансовых организаций (далее МФО). В 2020 году денежно-кредитная политика ЦБ России по снижению ключевой ставки с 6,25 до 4,5 (на март 2021), льготная государственная программа по ипотечному кредитованию под 6,5\% на приобретение жилья в новостройке привели к резкому росту выдачи потребительских и ипотечных кредитов.
Баринов Андрей Викторович

К.ю.н., доцент, Владимирский филиал Российской академии народного хозяйства и государственной службы; ФКОУ ВО «Владимирский юридический институm ФСИН Poccuu» barinov-vlad@inbox.ru

Кузнецова Наталья Владимировна Старший преподаватель, ФКОУ ВО «Владимирский юридический институт ФСИН России»

kuznezova-1963@mail.ru

Рябова Ольга Алексеевна

Преподаватель, ФКОУ ВО «Владимирский юридический институт ФСИН России» frau.lelya2012@yandex.ru

Аннотация. Статья посвящена вопросам наследования обязанностей по кредитному договору. На основе анализа норм гражданского законодательства, научных работ и разъяснений высшей судебной инстанции выделены особенности применения норм гражданского законодательства, регулирующего порядок наследования обязанностей по кредитному договору. Выявлены противоречия в судебных актах, разрешающих споры о взыскании с наследников задолженности по кредитному договору. Раскрыты проблемы, связанные с досрочным погашением наследниками кредита, полученного наследодателем для осуществления предпринимательской деятельности и недобросовестных действий кредитора при длительном не предъявлении им требований к наследникам о взыскании задолженности.

Сформулированы предложения по совершенствованию норм гражданского законодательства, регулирующие отношения по наследованию обязанностей по кредитному договору.

Ключевые слова: наследники, наследство, открытие наследства, кредитный договор, проценты за пользование кредитом, взыскание задолженности, злоупотребление правом.

По данным Банка России на 1 апреля 2020 общее число граждан, имеющих задолженность пред кредитными организациями, составляет 42 миллиона человек, из них 5,5 миллионов являются клиентами МФО [1]. По данным Национального бюро кредитных историй существенно вырос и средний размер потребительского кредита. В феврале 2021 года он достиг рекордной суммы в 264,8 тыс. рублей. Только за период пандемии кредиты физическим лицам выросли на 13,5\%. При этом реальные доходы россиян снизились на 3,5\%. По статистике ЦБ, на 1 марта 2021 года задолженность розничных клиентов перед банками составляла 20,8 трлн. руб. 
Доля просроченных ссуд на тот же период достигла 976 млрд. руб. [2].

Обязанность по возврату денежных средств, полученных в банке, по кредитному договору лежит на заемщике. Перевод долга по кредитному договору на других лиц при жизни заемщика допускается только с согласия банка (ст. 391 ГК РФ). В банковской практике для обеспечения возврата, выданных по кредитному договору денежных средств используются поручительство, залог имущества, а также страхование жизни и здоровья заемщика.

Одним из случаев перевода долга без согласия кредитора является наследование. Это универсальное правопреемство, предусматривающее переход имущества умершего гражданина к другим лицам [3].

Законодательство РФ в области наследования постулирует, что в состав наследства входят принадлежавшие наследодателю на день открытия наследства вещи, иное имущество, в том числе имущественные права и обязанности, а также задолженность по кредитному договору или договору займа.

Такой переход возможен, если в кредитные и заемные обязательства не включены указанные выше способы обеспечения исполнения обязательств.

Как указано в п. 60 постановления Пленума Верховного Суда Российской Федерации от 29 мая 2012 г. № 9 «О судебной практике по делам о наследовании» [4] ответственность по долгам наследодателя, включая кредитные обязательства, несут все принявшие наследство наследники, принимая во внимание и соответствующие публично-правовые образования, к которым перешло выморочное имущество. При этом юридическое значение имеет только факт принятия наследства - реализации наследником своих прав [5 С. 9]. Для возложения обязанности по кредитному договору на лиц, являющихся наследниками достаточно доказательства принятия наследства, при этом учитывается и фактическое принятие наследства. [6]. Что касается выморочного имущества, то при взыскании долга с публично-правового образования принятие имущества таким субъектом не имеет значение, так как для этого не требуется специальных актов.

Кредитные обязательства не связаны с личностью умершего и, следовательно, наследник, который принял наследство, приобретает статус должника и несет обязанности по исполнению кредитных обязательств наследодателя со дня открытия наследства. Как разъяснено в вышеуказанном Постановлении, если насле- додателем был заключен кредитный договор, то к лицу, вступившему в наследство, переходит обязанность погасить как оставшуюся на день открытия наследства сумму основного долга, так и так и проценты за пользование ею, при этом соблюдая сроки и порядок, предусмотренные договором.

Особенностью наследования кредитных обязательств является, во-первых, то, что досрочное возвращение суммы только с согласия кредитора за исключением случаев получения наследодателем кредита для личного, семейного, домашнего или иного использования, не связанного с предпринимательской деятельностью. Такой кредит может быть возвращен досрочно в полном объеме, но при условии уведомления об этом кредитора не менее чем за тридцать дней до дня такого возврата [3,4]. Во-вторых, в случае если наследодатель не исполнял обязанности по кредитному договору до момента смерти, то с наследников подлежит взысканию кроме оставшейся суммы кредита и процентов на нее еще и неустойка, если она установлена договором или проценты в соответствии со ст. 395 ГК РФ, но только до момента открытия наследства. Если наследники не будут исполнять обязанности по перешедшему к ним от наследодателя кредитному договору, то с них также подлежит взысканию сумма основного долга, проценты и неустойка. При этом, проценты могут быть взысканы с наследников только по истечении времени, которое необходимо для принятия наследства (приобретения выморочного имущества). Кроме того, если наследники не знали о кредитном договоре с участием наследодателя, а кредитор длительное время не предъявлял без уважительных причин требований к наследникам о погашении задолженности, то по указанию Верховного Суда РФ, такие действия кредитора, следует рассматривать как злоупотребление правом и суды на основании положений ст. 10 ГК РФ должны отказать во взыскании процентов по за весь период со дня открытия наследства [4]. В-третьих, необходимо помнить, что ответственность наследников по долгам наследодателя, учитывая кредитные обязательства, ограничивается только стоимостью перешедшего к ним наследственного имущества. Следовательно, если наследственного имущества недостаточно, или оно отсутствует, то требования по кредитному договору за счет имущества лиц, являющихся наследниками удовлетворению, не подлежат и обязательства наследодателя в этом случае должны быть прекращены невозможностью исполнения полностью или в части. [3,4] Скорей всего в такой ситуации, когда долгов у наследодателя больше чем имущества, или имущество вообще отсутствует, наследники вряд ли будут принимать такое наследство, поэтому кредиторам придется бороться за получение задолженности с соответствующего публично-правового образова- 
ния, как получателя выморочного имущества, при его наличии.

Приведенные разъяснения высшей судебной инстанции являются в настоящее время генеральной линией, которой следуют суды общей юрисдикции при рассмотрении дел, связанных с наследованием кредитных обязательств. Следует отметить, что до принятия Постановления Пленума Верховного Суда РФ № 9 судебная практика по делам о взыскании с наследников суммы долга и процентов по кредитному договору была далеко не однообразной. Граждане-наследники, соглашаясь оплатить сумму основного долга по кредитному договору наследодателя, пытались в суде признать незаконным взыскание с них процентов на эту сумму. В отдельных случаях, суды выносили решения в пользу граждан-наследников, отказывая банкам во взимании процентов по кредитному договору после открытия наследства. Указывая в судебных актах на незаконность возложения обязанности на наследников погашать проценты по кредитному договору, начисленные после смерти должника, суды связывали это с тем, что обязательства по их уплате прекратились в связи со смертью наследодателя [7] или ссылались на то, что пользование кредитом после смерти наследодателя прекратилось, а потому требования о взыскании процентов за пользование кредитом не подлежат удовлетворению [8]. Такие выводы судов в литературе обоснованно признавались ошибочными, так как требования к наследникам об уплате процентов за пользование кредитом, в том числе за период после смерти (с даты открытия наследства), правомерны и что наследники должны нести все обязанности по кредитному договору, в том числе и уплате процентов [9]. Однако даже после издания Постановления Пленума Верховного Суда РФ № 9 в ряде случаев суды продолжали принимать судебные акты, в которых требование о незаконности начисления процентов по кредиту после смерти наследодателя и до принятия наследниками наследства были удовлетворены [10]. В последующем такие акты отменялись кассационной инстанцией как незаконные и нарушающие нормы материального права, повлекших вынесение незаконного судебного постановления [11].

Сложившаяся на основании положений вышеуказанного Постановления, судебная практика по наследственным делам, связанных с обязанностями по кредитному договору, с одной стороны, не имеет каких-либо противоречий и не оставляет вопросов для дискуссии. Тем не менее, мы хотели бы обратить внимание на две проблемы, влияющие на права наследников при наследовании долга по кредитному договору.

Первая проблема связана с тем, что наследники после открытия наследства, зная о наличии кредитного договора у наследодателя, не всегда могут досрочно возвратить оставшуюся сумму долга, чтобы не платить дополнительные проценты. Так, если кредит был получен наследодателем для целей, связанных с личным, семейным, домашним или иным использованием, не связанным с предпринимательской деятельностью, то его наследники в соответствии с гражданским законодательством РФ после открытия наследства могут возвратить оставшуюся сумму долга досрочно только по истечении тридцати дней, с момента уведомления кредитора о своем желании погасить долг. А вот если наследодатель, будучи индивидуальным предпринимателем, получил кредит для осуществления предпринимательской деятельности, то его наследники могут вернуть оставшуюся сумму долга досрочно только с согласия кредитора (абз. 3 п. 2 ст. 810 ГК, п. 2 ст. 819 ГК РФ).). В этой связи возникает ситуация, когда наследники, получив по наследству «бизнес» с кредитом и, например, не желающие продолжать предпринимательскую деятельность обязаны будут выплачивать оставшуюся сумму кредита и проценты до окончания срока действия кредитного договора, если кредитор не согласен на возврат суммы долга раньше срока, установленного в договоре.

Таким образом, при наследовании обязанности по кредитному договору, когда кредит получен наследодателем для осуществления предпринимательской деятельности, наследники, которые не имели отношения к заключению такого договора будут обязаны длительное время до момента истечения срока действия договора выплачивать оставшуюся задолженность, если только кредитор не даст согласие на досрочное погашение или они должны будут заплатить штрафную санкцию за досрочное расторжение договора, что часто применяется в банковской практике. Такое положение вряд ли можно считать справедливым, так как оно противоречит принципу свободы договора, в том смысле, что понуждает участвовать в кредитном обязательстве лиц (наследников), которые его не заключали и добровольно не принимали на себя обязательство (п. 1 ст. 421 ГК РФ), а в силу обстоятельства (смерти заемщика), на основе правопреемства стали стороной договора. Так же едва ли можно признать обоснованным и установление тридцатидневного срока после уведомления кредитора для досрочного возврата суммы долга наследниками по кредитному договору, заключенному для непредпринимательских целей.

Исходя из этого, нам представляется целесообразным закрепить в ГК РФ положение, устанавливающее право наследников при принятии наследства, включающее обязанности по кредитному договору в любое время с момента открытия наследства досрочно воз- 
вратить оставшуюся сумму долга с уплатой процентов начисленных до дня возврата.

Другая проблема связана с тем, что в отдельных случаях кредитор (банки, МФО) осведомлены о лицах, принявших наследство, включающее обязанности по кредитному договору, но, действуя недобросовестно такой кредитор намеренно длительное время не предъявляют требования к наследникам с целью увеличения суммы долга с последующим взысканием в судебном порядке.

Так в одном из дел, рассмотренных Выборгским районным судом Санкт-Петербурга было установлено, что «Банк 29.03.2016 направил запрос нотариусу о предоставлении сведений о наследниках после умершего и получив необходимую информацию 14.04.2016 о наследниках и наследственном имуществе, с требованиями о досрочном возврате суммы кредита в адрес ответчиков Банк обратился спустя продолжительное время - 04.05.2017. Расценив такое поведение истца как злоупотребление правом, связав его с намеренным без уважительных причин длительным не предъявлением кредитором требований, суд основываясь на разъяснениях вышеуказанного Постановления Пленума, в удовлетворении иска о взыскании с ответчиков (наследников) задолженности по процентам отказал, указав, основываясь на законе, что наследники не должны отвечать за неблагоприятные последствия, которые наступили вследствие недобросовестных действий со стороны кредитора. Однако, при пересмотре в апелляционном порядке, вышестоящий суд отменил решение первой инстанции в части отказа в удовлетворении исковых требований о взыскании задолженности по просроченным процентам, при этом указав, что разъяснение Пленума относится к процентам за пользование чужими денежными средствами (ст. 395 ГК РФ), а проценты, предусмотренные ст. 395 ГК РФ, по своей природе отличаются от процентов, подлежащих уплате за пользование денежными средствами, предоставленными по договору займа и кредитному договору [12]. А вот в другом деле имеет место ситуация, когда, банк намерено не предъявлял требования о возврате задолженности более трех лет и судом было отказано в удовлетворении исковых требований о взыскании процентов на просроченный основной долг за весь период со дня открытия наследства, поскольку наследник не должен нести бремя ответственности за те неблагоприятные последствия, которые наступили вследствие недобросовестных действий со стороны кредитора. При этом суд апелляционной инстанции указал, что кредитор, злоупотребив своим правом, в нарушение ст. 10 ГК РФ, искусственно создал ситуацию, при которой размер подлежащих взысканию по кредитному договору процентов увеличился. [13].
Приведенные примеры, несмотря на достаточно четкое разъяснение, содержащееся в Постановлении Пленума свидетельствуют о существующих противоречиях в судебной практике по взысканию с наследников процентов на просроченный основной долг при длительном без уважительных причин не предъявлении кредитором требований к наследникам. Это противоречие обусловлено следующими обстоятельствами. С одной стороны, наследники, зная о перешедшей к ним задолженности по кредитному договору, как новые должники обязаны ее погасить. Предъявление требования в суд, к принявшим наследникам о взыскании такой задолженности - это право кредитора, реализовать которое он может в пределах сроков исковой давности [3] Поэтому, взыскание процентов на просроченный основной долг и штрафных санкций за неисполнение обязательства в пределах сроков исковой давности т.е. в пределах трех лет, является правомерным. С другой стороны, намеренное длительное не предъявление кредитором требований к наследникам по исполнению обязательств, вытекающих из кредитного договора, в отдельных случаях расцениваются судом как злоупотребление правом и на основании п. 2 ст. 10 ГК РФ суды отказывают в удовлетворении исковых требований о взыскании процентов на просроченный основной долг за весь период со дня открытия наследства. В таких случаях деятельность судов направлена на защиту интересов наследников от злоупотреблений со стороны кредиторов, которые, воспользовавшись ситуацией, намеренно значительно увеличивают сумму задолженности.

Такая двойственность в оценке представленной ситуации обусловлена на наш взгляд тем, что установленный в ГК РФ общий срок исковой давности для предъявления требований о взыскании задолженности по кредитному договору негативно влияет на права наследников, так как позволяет кредитору взыскать с них значительно больше, чем сумма задолженности на момент открытия наследства. Для устранения такого положения необходимо уменьшить срок исковой давности, для предъявления требований к наследникам или к наследственному имуществу, о взыскании задолженности по кредитному договору, сократив его до одного года со дня открытия наследства, что снимет вопрос о добросовестности действий кредитора.

Таким образом, нормы гражданского законодательства, регулирующие отношения по наследованию обязанностей по кредитному договору нуждаются в серьезном совершенствовании, с целью предоставления дополнительных гарантий прав наследников и устранения противоречия между правом кредитора на взыскание задолженности и недобросовестностью действий при его осуществлении. 


\section{ЛИТЕРАТУРА}

1. Россияне нагрузили себя долгами по максимуму // РБК Газета № 039 (3328) (2903) Финансы, 26 марта [сайт] URL: https://www.rbc.ru/newspaper/2021 /03/29/605da4a99a79479a7912674f.

2. Число россиян с кредитами и займами достигло 42 миллионов // Рамблер/финанс [сайт] URL: https://finance.rambler.ru/money/44753853-chislorossiyan-s-kreditami-i-zaymami-dostiglo-42-millionov/ (дата обращения: 23.04.2021.

3. Гражданский кодекс Российской Федерации. Часть третья: [Фе-деральный закон от 26 нояб. 2001 г. № 146-Ф3: принят Гос. Думой 1 нояб. 2001 г.] // С3 РФ. - 2001. - № 49, ст. 4552.

4. Постановление Пленума Верховного Суда РФ от 29 мая 2012 г. № 9 «0 судебной практике по делам о наследовании» //Бюллетень Верховного Суда Российской Федерации. 2012. № 7.

5. Слесарев С. Долги в наследство // Жилищное право. 2019. № 3. С. 7-18.

6. Апелляционное определение Московского городского суда от 18.12.2018 по делу N33-42262/2018// Доступ из справ.-правовой системы «Консультант Плюс».

7. Определение СК по гражданским делам Самарского областного суда от 01 декабря 2011 г. по делу № 33-12535/2011; Кассационное определение СК по гражданским делам Хабаровского краевого суда от 18 июля 2011 г. по делу N33-180 // Документ опубликован не был. Доступ из справ.-правовой системы «Консультант Плюс».

8. Определение СК по гражданским делам Московского областного суда от 14 февраля 2012 г. по делу N33-3697/2012 // Документ опубликован не был. Доступ из справ.-правовой системы «Консультант Плюс».

9. Боннер Е.А. Кредит в наследство // Юридическая работа в кредитной организации. 2014. № 4. Доступ из системы «Гарант».

10. Апелляционное определение Московского городского суда от 06 июля 2016 г. N33-25847/16 // Документ опубликован не был. Доступ из системы «Гарант».

11. Определение СК по гражданским делам Верховного Суда РФ от 20 июня 2017 г. N5-КГ17-79 // Документ опубликован не был. Доступ из системы «Гарант».

12. Апелляционное определение СК по гражданским делам Санкт-Петербургского городского суда от 08 октября 2018 г. по делу N33-21294/2018 // Документ опубликован не был. Доступ из системы «Гарант».

13. Апелляционное определение СК по гражданским делам Московского городского суда от 22 июня 2020 г. по делу N33-8841/2020 // Документ опубликован не был. Доступ из системы «Гарант».

(с) Баринов Андрей Викторович ( barinov-vlad@inbox.ru ),

Кузнецова Наталья Владимировна ( kuznezova-1963@mail.ru ), Рябова Ольга Алексеевна ( frau.lelya2012@yandex.ru ).

Журнал «Современная наука: актуальные проблемы теории и практики» 